\title{
The effect of drought and interspecific interactions on depth of water uptake in deep- and shallow-rooting grassland species as determined by $\delta^{18} \mathrm{O}$ natural abundance
}

\author{
N. J. Hoekstra ${ }^{1,2}$, J. A. Finn ${ }^{1}$, D. Hofer ${ }^{2,3}$, and A. Lüscher ${ }^{2}$ \\ ${ }^{1}$ Teagasc, Environment Research Centre, Johnstown Castle, Wexford, Ireland \\ ${ }^{2}$ Agroscope, Institute for Sustainability Sciences ISS, 8046 Zürich, Switzerland \\ ${ }^{3}$ ETH Zürich, Institute of Agricultural Sciences, 8092 Zürich, Switzerland
}

Correspondence to: J. A. Finn (john.finn@teagasc.ie)

Received: 5 February 2014 - Published in Biogeosciences Discuss.: 15 March 2014

Revised: 4 June 2014 - Accepted: 4 July 2014 - Published: 25 August 2014

\begin{abstract}
Increased incidence of drought, as predicted under climate change, has the potential to negatively affect grassland production. Compared to monocultures, vertical belowground niche complementarity between shallow- and deeprooting species may be an important mechanism resulting in higher yields and higher resistance to drought in grassland mixtures. However, very little is known about the belowground responses in grassland systems and increased insight into these processes may yield important information both to predict the effect of future climate change and better design agricultural systems to cope with this.

This study assessed the effect of a 9-week experimental summer drought on the depth of water uptake of two shallowrooting species (Lolium perenne L. and Trifolium repens L.) and two deep-rooting species (Cichorium intybus L. and Trifolium pratense L.) in grassland monocultures and fourspecies mixtures by using the natural abundance $\delta^{18} \mathrm{O}$ isotope method. We tested the following three hypotheses: (1) drought results in a shift of water uptake to deeper soil layers, (2) deep-rooting species take up a higher proportion of water from deeper soil layers relative to shallow-rooting species, and (3) as a result of interspecific interactions in mixtures, the water uptake of shallow-rooting species becomes shallower when grown together with deep-rooting species and vice versa, resulting in reduced niche overlap.

The natural abundance $\delta^{18} \mathrm{O}$ technique provided novel insights into the depth of water uptake of deep- and shallowrooting grassland species and revealed large shifts in depth
\end{abstract}

of water uptake in response to drought and interspecific interactions.

Compared to control conditions, drought reduced the proportional water uptake from $0-10 \mathrm{~cm}$ soil depth (PCWU $\mathrm{P}_{0-10}$ ) of $L$. perenne, $T$. repens and $C$. intybus in monocultures by on average $54 \%$. In contrast, the $\mathrm{PCWU}_{0-10}$ of $T$. pratense in monoculture increased by $44 \%$, and only when grown in mixture did the $\mathrm{PCWU}_{0-10}$ of $T$. pratense decrease under drought conditions. In line with hypothesis (2), in monoculture, the $\mathrm{PCWU}_{0-10}$ of shallowrooting species $L$. perenne and $T$. repens was 0.53 averaged over the two drought treatments, compared to 0.16 for the deep-rooting $C$. intybus. Surprisingly, in monoculture, water uptake by $T$. pratense was shallower than for the shallowrooting species $\left(\mathrm{PCWU}_{0-10}=0.68\right)$.

Interspecific interactions in mixtures resulted in a shift in the depth of water uptake by the different species. As hypothesised, the shallow-rooting species $L$. perenne and $T$. repens tended to become shallower, and the deep-rooting $T$. pratense made a dramatic shift to deeper soil layers (reduction in $\mathrm{PCWU}_{0-10}$ of $58 \%$ on average) in mixture compared to monoculture. However, these shifts did not result in a reduction in the proportional similarity of the proportional water uptake from different soil depth intervals (niche overlap) in mixtures compared to monocultures.

There was no clear link between interspecific differences in depth of water uptake and the reduction of biomass production under drought compared to control conditions (drought resistance). Cichorium intybus, the species with 
water uptake from the deepest soil layers was one of the species most affected by drought. Interestingly, T. pratense, which was least affected by drought, also had the greatest plasticity in depth of water uptake. This suggests that there may be an indirect effect of rooting depth on drought resistance, as it determines the potential plasticity in the depth of water uptake.

\section{Introduction}

Both the frequency and the intensity of extreme weather events is predicted to increase under climate change (IPCC, 2013). Climate models predict that the climate in Central Europe will be characterised by increasing temperatures, reduced summer precipitation and increased frequency of extreme events (Christensen, 2003; Schär, 2004). These discrete events include droughts, heat-waves and storms, and can have a large impact on a variety of ecosystem functions and services (Lehner et al., 2006). Increased incidence of drought has the potential to disrupt crop and grassland production, and there is a need to consider adaptation options to support global food security. Research on temperate grasslands shows a strong negative effect of drought on aboveground production (Gilgen and Buchmann, 2009; Grime et al., 2000; Kahmen et al., 2005; Vogel et al., 2012; De Boeck et al., 2008). However, there is high variability in the observed responses. This variability could be related to differences across experiments in the severity (Vicca et al., 2012) and timing of the drought stress, as well as differences in plant functional types present in the ecosystem. In the current study, we focus on studying different plant functional types, i.e. deep-rooting and shallow-rooting grassland species.

It is often assumed that plants respond to water shortage in the (upper part of the) soil by shifting water extraction to deeper soil layers that generally have higher levels of water (Sharp and Davies, 1985; Garwood and Sinclair, 1979). By doing so, plants are able to delay loss of turgor, prevent stomatal closure, and maintain a high rate of photosynthesis. Rather than by a complete adjustment of the root density profile, plants can adapt to drought by rapidly developing fine roots (Coelho and Or, 1999), or by increasing the activity and efficiency of deep roots (Sharp and Davies, 1985; Kulmatiski and Beard, 2013). More deeply rooted plants are more likely to survive extended periods of drought by accessing deeper soil layers that contain higher soil moisture levels (Chaves et al., 2003). However, there are quite varied responses in the few studies of grassland plants that have investigated the effect of drought on rooting depth (Skinner, 2008; Garwood and Sinclair, 1979; Jupp and Newman, 1987), or on the depth of water uptake (Asbjornsen et al., 2008; Kulmatiski and Beard, 2013; Nippert and Knapp, 2007a, b; Grieu et al., 2001) and very few studies have been conducted in tem- perate grassland systems with grasses and herbaceous plants only (Grieu et al., 2001; Prechsl, 2013).

Plant species diversity in both semi-natural (e.g. Tilman et al., 1996, 2002; Hector et al., 1999; Kennedy et al., 2002) and agricultural (e.g. Finn et al., 2013; Kirwan et al., 2007; Nyfeler et al., 2009, 2011) ecosystems has been related to higher primary production, nutrient retention, resistance to weed invasion and stability in response to disturbance, and is often attributed to complementarity in a variety of plant traits and niches and interspecific interactions. One commonly proposed mechanism to achieve functional complementarity is belowground vertical niche complementarity between shallow-rooting and deep-rooting species (Berendse, 1982; von Felten and Schmid, 2008).

When grown in monoculture, a species with roots that mainly occupy the shallow soil layers (shallow-rooting species) will be expected to mainly utilise water and nutrients from shallow soil layers (since they have no or very few roots in deep layers). Deep-rooting species in monoculture have roots that occupy deeper soil layers and can also access water and nutrients from deeper soil layers. However, the thick taproots of these species generally have a low root length density ( $\mathrm{cm}$ root length per $\mathrm{cm}^{3}$ soil volume), and thus tend to have lower resource uptake from shallow soil layers. A combination of these two types of species with their complementary strengths in mixture could result in a more complete exploitation of available soil resources than could be achieved by either species grown in monoculture. This complementarity could be enhanced if the belowground niche occupation of a given species were to move away from zones of intense resource competition with neighbours when grown in mixture (von Felten et al., 2009; Mommer et al., 2010). In such a scenario, deep-rooting species can be expected to root even deeper and shallow-rooting species even shallower when grown in mixtures as a result of the shift in vertical soil niche occupation in mixtures compared to monocultures. Ultimately, this total increase in utilisation of water and nutrients may lead to higher above-ground biomass production than expected from a combination of monoculture performances.

However, the majority of research in grassland systems has focused on aboveground responses, since the measurement of belowground plant biomass is much more labour intensive. Also, it is very hard to distinguish the roots of different species grown in mixtures in the field (see Mommer et al., 2008). Even when the roots of different species are identified, the presence and abundance of roots is not necessarily equivalent to root activity (Kulmatiski and Beard, 2013). Thus, insight into and evidence of belowground vertical niche complementarity and niche shifts of individual species in response to drought and interspecifc interactions is very limited.

Work is on-going to address these methodological challenges. Recently, ${ }^{15} \mathrm{~N}$ tracers have been used to study nitrogen uptake patterns from different soil depths in grasslands 
with varying diversity levels (Pirhofer-Walzl et al., 2013; von Felten et al., 2009). As a measure of soil water utilisation, the natural abundance of $\delta^{18} \mathrm{O}$ in soil and plant water can be used to measure the depth of water uptake of individual species (Durand et al., 2010; Dawson and Ehleringer, 1993; Nippert and Knapp, 2007a; Asbjornsen et al., 2008). Enabled by these methodological advances, new insights into these processes can yield important information with which to predict both the effect of future climate change on grassland production, and to better design agricultural systems with improved resource utilisation and resistance to drought.

The objective of this study was to use the natural abundance $\delta^{18} \mathrm{O}$ isotope method to assess the effect of experimentally induced drought on the depth of water uptake of shallow-rooting and deep-rooting species in intensively managed grassland mixtures and monocultures. We tested the following three hypotheses: (1) summer drought will result in a shift of water uptake to deeper soil layers, (2) deep-rooting species take up a higher proportion of water from deeper soil layers relative to shallow-rooting species, which is expected to give them an advantage under drought conditions, and (3) interspecific interactions result in a shift in the depth of water uptake of individual species grown in mixtures compared to monocultures. We hypothesise that water uptake by shallow-rooting species will become shallower when grown together with deep-rooting species and vice versa, resulting in reduced niche overlap.

\section{Materials and methods}

\subsection{Site and maintenance}

We report measurements from two experiments that were conducted at Tänikon Research Station, Aadorf $\left(47^{\circ} 48^{\prime} \mathrm{N}\right.$, $\left.8^{\circ} 91^{\prime} \mathrm{E}\right)$ and Reckenholz, Zürich $\left(47^{\circ} 43^{\prime} \mathrm{N}, 8^{\circ} 53^{\prime} \mathrm{E}\right)$ in Switzerland (Table 1). The experimental site at Tänikon was situated on a brown earth (topsoil sandy loam, subsoil clay) and the site at Reckenholz was a cambisol (topsoil 20-30\% clay, subsoil 30-40\% clay). Swards were sown in August 2010 and 2011 (Tänikon and Reckenholz, respectively) on $3 \mathrm{~m} \times 5 \mathrm{~m}$ plots. Plots were cut seven times per year in Tänikon (2011), including a clearing cut in April, and six times in Reckenholz (2012). Plots received 145 and $200 \mathrm{~kg} \mathrm{~N} \mathrm{ha}^{-1} \mathrm{yr}^{-1}$ (Tänikon and Reckenholz, respectively) split over five applications, and enough $\mathrm{P}$ and $\mathrm{K}$ as to be nonlimiting for intensively managed grassland.

\subsection{Experimental design}

Four grassland species were selected based on their expected rooting depth: two shallow-rooting species, Lolium perenne L. (L. perenne) cultivar (cv.) Alligator and Trifolium repens L. (T. repens) cv. Hebe, and two deep-rooting species, $\mathrm{Ci}$ chorium intybus L. (C. intybus) cv. Puna II and Trifolium pratense L. (T. pratense) cv. Pastor in Tänikon and cv. Dafila in Reckenholz. L. perenne and $T$. repens generally have the bulk of their roots in the top $10 \mathrm{~cm}$, whereas $C$. intybus and T. pratense have tap roots that allow access to deeper soil depths (Brown et al., 2003; Black et al., 2009). All four species were sown in four monocultures and in one mixture with equal proportions of all four species, resulting in five different plant communities. Monocultures of $L$. perenne, $C$. intybus, $T$. repens and $T$. pratense were sown with 30, 6.5, 16 and $16.4 \mathrm{~kg}$ germinable seeds $\mathrm{ha}^{-1}$, respectively.

Using rainout shelters, half of the plots were subjected to a drought treatment of 9 weeks duration (spanning two regrowth periods, Table 1), with three replicate plots per treatment. The tunnel-shaped shelters consisted of steel frames of $5.5 \mathrm{~m} \times 3 \mathrm{~m} \times 1.4 \mathrm{~m}$ height, covered with $1.5 \mu \mathrm{m}$ thick transparent plastic foil (Gewächshausfolien-Zuschnitt UV4, 190my) with the opposing ends left uncovered. Gutters were installed to prevent the water from flowing onto adjacent plots, and a ventilation opening at the top and bottom $50 \mathrm{~cm}$ was included to stimulate air circulation and minimise temperature increases underneath the shelters.

Air temperature and relative humidity $(\mathrm{RH})$ were measured at $80 \mathrm{~cm}$ height with combined temperature and $\mathrm{RH}$ probes (Decagon EHT durable RH/temperature sensor) in four mixture plots at Tänikon and six mixture plots at Reckenholz, respectively (both control and drought plots) and logged hourly (EM50, Decagon). Rainfall for the two experiments was recorded at the weather stations located at Tänikon Research Centre and ART, Reckenholz, Zürich which were within $2 \mathrm{~km}$ distance of the experimental sites. Photosynthetically active radiation (PAR) was measured above the canopy of all plots subjected to drought (underneath the shelter) and of control plots on five occasions during the drought period using a ceptometer (AccuPAR LP80, Decagon Devices, USA).

\subsection{Sampling}

At the end of the drought period, dry matter yield of the aboveground biomass was determined by cutting a $5 \mathrm{~m} \times 1.5 \mathrm{~m}$ strip at $7 \mathrm{~cm}$ height from the centre of each plot using a Hege plot harvester. The species proportions were determined by cutting a $50 \mathrm{~cm} \times 50 \mathrm{~cm}$ square from the centre of each plot using electric shears and sorting the herbage into the four sown species, dead material and unsown species. All herbage samples were oven-dried in a forced air oven at $60^{\circ} \mathrm{C}$ for $48 \mathrm{~h}$ to determine the dry matter content.

$\delta^{18} \mathrm{O}$ natural abundance of soil water and plant water was used to assess the depth of water uptake of individual species. The lower evaporation rate of heavy isotopes increases the concentration of ${ }^{18} \mathrm{O}$ in water at the soil surface. Diffusion of the isotopes in soil then follows from the top of the profile downwards. This results in a vertical gradient in isotopic composition of water in the soil (Durand et al., 2007). No isotopic fractionation occurs during soil water uptake by root systems, and therefore the composition of plant xylem water 
Table 1. Overview of dates and micrometeorological conditions under drought and control treatment during the final week of the drought period in Tänikon 2011 and Reckenholz (2012).

\begin{tabular}{|c|c|c|c|c|c|c|}
\hline & \multicolumn{3}{|c|}{ Tänikon (2011) } & \multicolumn{3}{|c|}{ Reckenholz (2012) } \\
\hline Sowing date & \multicolumn{3}{|c|}{ August 2010} & \multicolumn{3}{|c|}{ August 2011} \\
\hline Start drought period & \multicolumn{3}{|c|}{$22 / 06 / 2011$} & \multicolumn{3}{|c|}{ 06/07/2012 } \\
\hline Duration drought period (weeks) & \multicolumn{3}{|c|}{9} & \multicolumn{3}{|c|}{9} \\
\hline Rain excluded during drought (mm) & \multicolumn{3}{|c|}{306} & \multicolumn{3}{|c|}{247} \\
\hline Rain exclusion (\% of annual rainfall) & \multicolumn{3}{|c|}{$33 \%$} & \multicolumn{3}{|c|}{$21 \%$} \\
\hline & Control & Drought & $\%$ change & Control & Drought & $\%$ change \\
\hline Relative humidity & 0.79 & 0.77 & -3 & 0.87 & 0.86 & -1 \\
\hline Mean air temperature $\left({ }^{\circ} \mathrm{C}\right)$ & 20.3 & 21.1 & 4 & 15.6 & 16.0 & 3 \\
\hline Maximum air temperature $\left({ }^{\circ} \mathrm{C}\right)$ & 27.7 & 29.4 & 6 & 20.5 & 21.7 & 6 \\
\hline Mean soil temperature at $5 \mathrm{~cm}$ depth $\left({ }^{\circ} \mathrm{C}\right)$ & 19.1 & 19.7 & 3 & 16.3 & 18.6 & 14 \\
\hline Photosynthetically active radiation $\left(\mu \mathrm{mol} \mathrm{m}{ }^{-2} \mathrm{~s}^{-1}\right)$ & 1115 & 998 & -10 & 1611 & 1164 & -28 \\
\hline
\end{tabular}

is an indicator of the mean depth of water uptake (Dawson et al., 2002).

Approximately 1 week before the end of the drought period, crown roots and stem bases (up to $1.5 \mathrm{~cm}$ above soil level) were collected from five to eight tillers (depending on tiller weight) of all four sown species. Samples were taken from two replicate plots of all treatment combinations. For L. perenne, the outer sheath, which may be subject to transpiration and therefore have an altered $\delta^{18} \mathrm{O}$ signal (Durand et al., 2007) was removed. At the same time, three $2 \mathrm{~cm}$ diameter soil cores were taken to $40 \mathrm{~cm}$ depth per plot and divided into four segments for Tänikon $2011(0-10,10-20$, $20-30$ and $30-40 \mathrm{~cm})$ and five segments for Reckenholz 2012 $(0-10 \mathrm{~cm}$ segment split into $0-5 \mathrm{~cm}$ and $5-10 \mathrm{~cm})$. All samples were taken in the core plot area, excluding the outer 1 $\mathrm{m}$ border of the plot. All plant samples and a bulked subsample of the soil material were stored frozen in airtight glass vials (Exetainers, Labco, UK). The remainder of the soil material was oven-dried at $100{ }^{\circ} \mathrm{C}$ for $48 \mathrm{~h}$ to determine the soil moisture content (SMC). Water from the soil and plant samples was extracted using cryogenic vacuum distillation (Ehleringer and Osmond, 1989).

Water samples were analysed for oxygen 18 isotopes at the Boston University Stable Isotope Laboratory on a MultiFlow (GV Instruments, Lyon, France) interfaced to an IsoPrime isotope ratio mass spectrometer (GV Instruments, Lyon, France). The procedure is based on the headspace equilibration technique (Socki et al., 1992). A total of $100 \mathrm{~mL}$ of water was placed in a Labco vial and capped. The vials were placed in a Gilson Autosampler and flushed with a mix of $5 \% \mathrm{CO}_{2} / 95 \% \mathrm{He}$, and then allowed to equilibrate for $8 \mathrm{~h}$ at $40^{\circ} \mathrm{C}$. During this time the oxygen isotopes in the water fully exchange with the oxygen in the $\mathrm{CO}_{2}$. The headspace was subsampled and measured against a reference $\mathrm{CO}_{2}$ gas. Samples were calibrated using IAEA standards and normalized to the V-SMOW/SLAP scale. Check standards were run every 10 samples to ensure quality control and to correct for drift (if needed), and precision was usually $0.1 \%$ or better.

\subsection{Data analysis}

We used two methods to assess the ${ }^{18} \mathrm{O}$ data. Firstly, we used the direct inference approach (Asbjornsen et al., 2008; Brunel et al., 1995) to determine the mean soil depth from which each of the four species was extracting water. In this approach, the $\delta^{18} \mathrm{O}$ isotopic signature of plant stem water is compared with the $\delta^{18} \mathrm{O}$ signature of water at varying depths in the soil profile to determine at which depth the two values correspond to each other (Fig. S1 in the Supplement). This soil depth is interpreted as the mean depth from which the plant extracted its water during the preceding time period. This approach assumes that roots preferentially take soil water from a single depth zone during any given period of time (Asbjornsen et al., 2007).

Secondly, we applied the IsoSource stable isotope mixing model (Phillips and Gregg, 2003) to quantitatively determine the proportional contribution of each of the sources (i.e. 4-5 soil depth intervals, as in Methods) to the plant stem water $\delta^{18} \mathrm{O}$ signature. In this method, all possible combinations of each source contribution (1-100\%) were examined in $1 \%$ increments. Combinations of source contributions that summed to the observed plant stem $\delta^{18} \mathrm{O}$ signature within a small tolerance $(1 \%)$ were considered to be feasible solutions. Based on this set of all feasible solutions, the frequency distribution, mean and 1-99th percentile range of the potential proportional contribution of each source were determined (for details, see Phillips and Gregg, 2003). Uncertainty associated with the proportional contributions from the $0-5$ and 5-10 cm layer (Reckenholz, 2012) was high (i.e. the range of potential source contributions was relatively large). Therefore we used the a posteriori approach outlined by Phillips et al. (2005) to combine the $0-5 \mathrm{~cm}$ and $5-10 \mathrm{~cm}$ layer into one single layer $(0-10 \mathrm{~cm})$. To this end, we imported the output 
files from the IsoSource model containing all the feasible source contribution solutions into Excel, and created the aggregate $0-10 \mathrm{~cm}$ soil layer as the sum of the $0-5$ and $5-10 \mathrm{~cm}$ soil layer. Subsequently, we calculated the new mean and range for the aggregated $0-10 \mathrm{~cm}$ layer. Both the direct inference and the IsoSource method assume that the only water source was soil water in the $0-40 \mathrm{~cm}$ soil depth interval.

For Tänikon 2011, all the plant samples of L. perenne, $T$. repens and $C$. intybus and one sample of $T$. pratense (control, mixture, replicate 1) were contaminated during the cryogenic vacuum distillation process due to a faulty vacuum, and therefore we only present the results for $T$. pratense for Tänikon 2011. To avoid the risk of over-interpreting the data and to increase the comparability with the direct inference approach we focus on the proportional contribution to water uptake from the $0-10 \mathrm{~cm}$ soil depth interval (instead of all four soil depth intervals) calculated by the IsoSource model.

We aimed to assess whether the vertical soil niche occupation of different species became less similar in mixture compared to monoculture (hypothesis 3). To this end, we calculated the proportional similarity index (PS) (Colwell and Futuyma, 1971) of the proportional contribution to water uptake of the $0-10$ and $10-40 \mathrm{~cm}$ soil depth interval $\left(p_{\mathrm{i}}\right)$, between pairs of species (species 1 and 2) for the Reckenholz 2012 data:

$\mathrm{PS}=1-0.5 \sum_{i=1}^{n}\left|p_{1 \mathrm{i}}-p_{2 \mathrm{i}}\right|$.

The value of PS is minimum (0) when there is no overlap of the proportional water contribution of the two soil layers between two species within a species pair, and is maximum (1) when there is complete overlap.

\subsection{Statistical analysis}

Data were analysed by analysis of variance (ANOVA), considering the within-plot correlation of soil depth data and species where necessary by specifying a random plot grouping factor, and subsequent testing using a linear mixed model (Pinheiro and Bates, 2009). The full models consisted of all main effects and higher-order interactions, and were run separately for the two experiments. Differences among treatment levels were analysed based on model contrasts.

Main factors for soil moisture content and $\delta^{18} \mathrm{O}$ values of the soil were water supply (drought and control), community (L. perenne monoculture, $T$. repens monoculture, $C$. intybus monoculture, $T$. pratense monoculture and the equiproportional mixture) and soil depth interval (0-10, 10-20, $20-30$ and $30-40 \mathrm{~cm}$ ) (Table $S 1$ in the Supplement). With respect to dry matter yield of the aboveground biomass, main factors were water supply and community (Table S2 in the Supplement), while for the species' proportions in the mixture, main factors were water supply and species (L. perenne, T. repens, $C$. intybus, T. pratense) (Table S3 in the Supplement). The main factors for the mean inferred depth of water uptake (direct inference approach) and the proportional contribution to plant water uptake of the $0-10 \mathrm{~cm}$ soil depth interval (IsoSource model) were water supply, diversity (monoculture, mixture) and species (the latter for 2012 only) (Table S4 in the Supplement). For the proportional similarity (Eq. 1) the main factors were water supply, diversity and species pair (L. perenne $-T$. repens, L. perenne$C$. intybus, $L$. perenne-T. pratense; T. repens-C. intybus, $T$. repens $-T$. pratense and $C$. intybus $-T$. pratense) or rootingdepth pair (Shallow, Mixed, Deep) (Table S5 in the Supplement), in which "Mixed" refers to species-pairs consisting of a shallow- and deep-rooting species. All statistical analyses were carried out using the statistical software R (R Development Core Team, 2012).

\section{Results}

\subsection{Growth conditions}

During the drought period, a total of 306 and $247 \mathrm{~mm}$ of rain was excluded from the drought plots, which corresponded to 33 and $21 \%$ of the total annual rainfall for Tänikon 2011 and Reckenholz, 2012, respectively (Table 1). The mean air temperature under the shelters was slightly higher $(0.8$ and 0.4 ${ }^{\circ} \mathrm{C}$ increase for Tänikon (2011) and Reckenholz (2012), respectively), whereas the relative humidity was slightly lower ( -3 and $-1 \%$, respectively) (Table 1 ). The incoming PAR was 11 and $28 \%$ lower underneath the shelters compared to control plots in Tänikon (2011) and Reckenholz (2012), respectively (Table 1). Under control conditions, the soil moisture content ranged from 0.33 and $0.20 \mathrm{~g}$ water per g dry soil in the $0-10 \mathrm{~cm}$ soil depth interval to 0.28 and $0.18 \mathrm{~g}$ water per $\mathrm{g}$ dry soil in the $30-40 \mathrm{~cm}$ soil depth interval for Tänikon (2011) and Reckenholz (2012), respectively. In both experiments, soil moisture content was significantly lower under drought compared to control conditions $(p<0.001)$. The difference in soil moisture content between control and drought was on average 0.15 and $0.11 \mathrm{~g}$ water per $\mathrm{g}$ dry soil in the $0-10 \mathrm{~cm}$ soil depth interval, but was only 0.03 and $0.06 \mathrm{~g}$ water per $\mathrm{g}$ dry soil in the $30-40 \mathrm{~cm}$ soil depth interval for Tänikon (2011) and Reckenholz (2012), respectively, resulting in a significant water supply $\times$ depth interaction $(p<0.001$, Fig. 1a, b and Table S1 in the Supplement).

\subsection{Aboveground biomass}

There was a significant reduction in herbage dry matter yield under drought conditions of $18 \%(p<0.05)$ for Tänikon and $41 \%$ for Reckenholz ( $p<0.001$ ) (Tables 2 and S2 in the Supplement). Overall, there was a significant effect of community $(p<0.001)$ on the herbage dry matter yield. Yield values were highest for the $T$. pratense monoculture followed by the equi-proportional mixture and lowest for the L. perenne monocultures (mean dry matter yield of 2854, 2211 and $671 \mathrm{~kg} \mathrm{ha}^{-1}$, respectively). The yield reduction - for Tänikon 


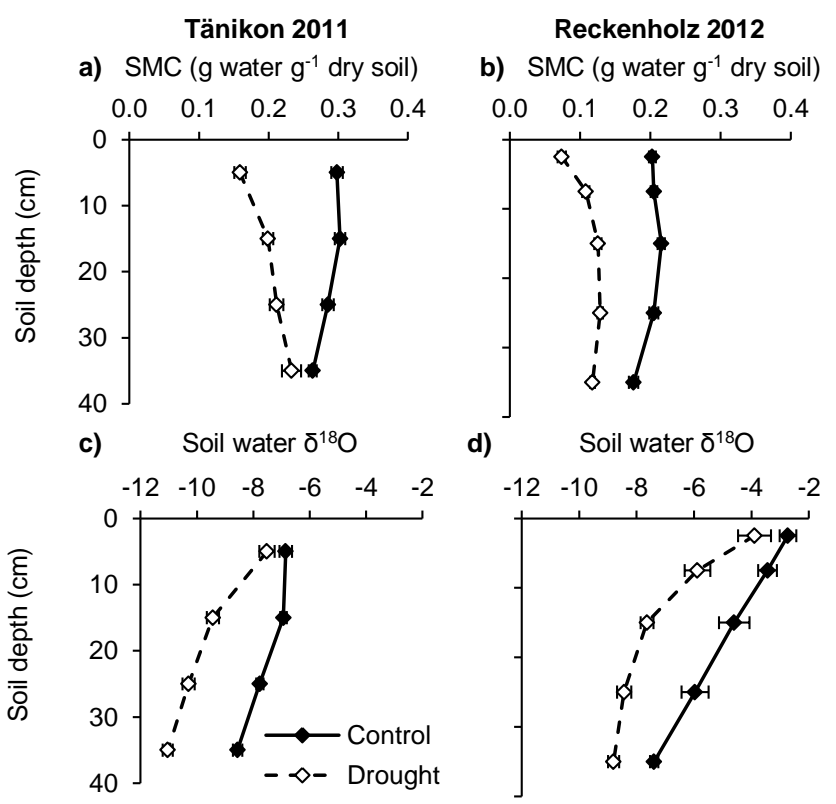

Figure 1. Mean $( \pm$ SE) soil moisture content (SMC, $g$ water $g$ dry soil $\left.{ }^{-1}\right)(\mathbf{a}, \mathbf{b})$ and $\delta^{18} \mathrm{O}$ value of the soil water extracts $(\mathbf{c}, \mathbf{d})$ throughout the soil profile for control and drought plots averaged across the different communities in Tänikon (2011) and Reckenholz (2012) $(n=10)$.

(2011) and Reckenholz (2012), respectively - under drought conditions was highest for $L$. perenne ( 65 and $76 \%$ ) and $C$. intybus (37 and $62 \%$ ), and lowest for T. pratense ( 2 and $21 \%)$ and in 2012 this resulted in a borderline significant $(p=0.08)$ community $\times$ water supply interaction (Tables 2 and $\mathrm{S} 2$ in the Supplement).

In mixture, T. pratense was always the dominant species with an average proportional contribution to dry matter yield of 0.55 , whereas the proportions of the other species were on average $0.20,0.08$ and 0.08 for $L$. perenne, $T$. repens and C. intybus, respectively, resulting in a significant $(p<0.001)$ effect of species on the species proportion (Tables 2 and S3 in the Supplement).

\subsection{Soil water $\delta^{18} \mathrm{O}$}

Soil water $\delta^{18} \mathrm{O}$ was significantly more negative under drought compared to control conditions $(p<0.001$, Table S1 in the Supplement). Generally, the $\delta^{18} \mathrm{O}$ values of soil water were highest (least negative) in the top $10 \mathrm{~cm}$ and values significantly declined at deeper soil depth intervals $(p<0.001$, Fig. 1c, d and Table S1 in the Supplement). The difference between control and drought plots was smaller at shallow compared to deep soil depth intervals, resulting in a significant water supply $\times$ depth interaction $(p<0.001$, Fig. $1 \mathrm{c}, \mathrm{d}$ and Table S1 in the Supplement).

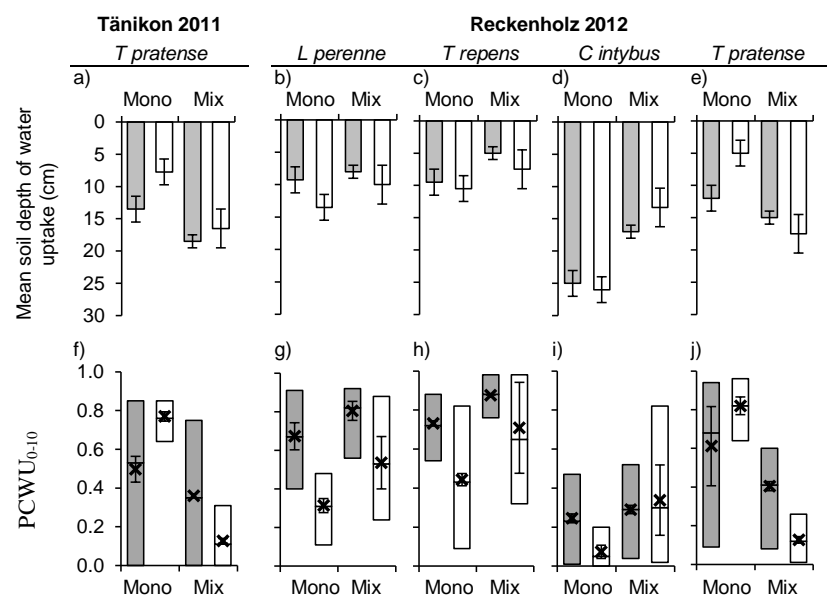

Figure 2. The mean soil depth of water uptake (cm, a-e) and the proportional contribution to plant water uptake of the $0-10 \mathrm{~cm}$ soil depth interval $\left(\mathrm{PCWU}_{0-10}\right)(\mathbf{f}-\mathbf{j})$ of the two shallow-rooting $(L$. perenne and $T$. repens) and deep-rooting (C. intybus and T. pratense) species grown in monoculture (Mono) or mixture (Mix) under control (shaded bars) or drought (white bars) conditions in Tänikon (2011) (T. pratense only) and Reckenholz (2012). The mean soil depth of water uptake is based on the direct inference approach (see Fig. S1 in the Supplement). The proportional contribution to plant water uptake $(\mathbf{f}-\mathbf{j})$ is based on the frequency distribution output from the IsoSource model and lower, middle and upper boundaries of the bars represent the 1 st percentile, 50th percentile and 99th percentile of the proportional contribution, respectively (see Fig. S2 in the Supplement for all soil depth intervals). The mean $(x)$ and SE of the mean proportional contribution are also included $(n=2$ in all cases except for the Tänikon T. pratense control mixture and the Reckenholz T. repens control mixture, where $n=1$ ).

\subsection{Depth of water uptake}

\subsubsection{Comparison of methods}

The mean inferred soil depth of water uptake was $13 \mathrm{~cm}$ (Fig. 2a-e) and varied from $5 \mathrm{~cm}$ for T. repens (control, mixture, see Fig. 2c) to $26 \mathrm{~cm}$ for C. intybus (drought, monoculture, Fig. 2d). The mean proportional contribution of the $0-10 \mathrm{~cm}$ soil layer to plant water uptake $\left(\mathrm{PCWU}_{0-10}\right)$ was on average 0.48 (Fig. $2 \mathrm{f}-\mathrm{j}$ ) and ranged from 0.07 to 0.88 , corresponding to the treatments with the lowest and highest depth of soil water uptake, respectively. In general there was a good correlation between the two methods to assess the depth of water uptake based on $\delta^{18} \mathrm{O}$ analysis $(r=0.86$, Fig. 3), but the IsoSource method resulted in more statistically significant effects, as outlined below and in Table S4 in the Supplement. There was a strong agreement between the T. pratense data from Tänikon (2011) and Reckenholz (2012) (Fig. 2), giving confidence in the robustness of the results.

The proportional contribution to plant water uptake of the $10-20,20-30$ and $30-40 \mathrm{~cm}$ soil depth interval was very similar and on average $0.16,0.17$ and 0.19 , respectively (Fig. S2 


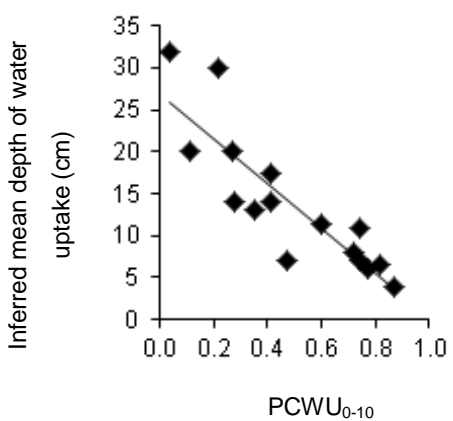

Figure 3. Correlation between the proportional contribution to water uptake of the $0-10 \mathrm{~cm}$ soil depth interval $\left(\mathrm{PCWU}_{0-10}\right)$ with the inferred mean depth of water uptake $(r=0.86)$.

in the Supplement). Therefore, we present a two-pool model, in which the $10-40 \mathrm{~cm}$ soil depth interval is the mirror image of the $0-10 \mathrm{~cm}$ soil depth interval.

\subsubsection{Drought effect}

When grown in monoculture, the $\mathrm{PCWU}_{0-10}$ of L. perenne, T. repens and $C$. intybus was reduced by $0.35(p<0.05), 0.29$ $(p=0.06)$ and $0.17(p=0.27)$, respectively under drought compared to control conditions, indicating a shift to deeper soil layers (Figs. $2 \mathrm{f}-\mathrm{j}$ and $4 \mathrm{a}$ ). In contrast, the $\mathrm{PCWU}_{0-10}$ of $T$. pratense grown in monoculture increased by 0.27 $(p<0.05)$ and $0.20(p=0.17)$ in 2011 and 2012, respectively.

When grown in mixture, the effect of drought on the $\mathrm{PCWU}_{0-10}$ of $L$. perenne and $T$. repens was in the same direction but less pronounced compared to when grown in monoculture (reduction in $\mathrm{PCWU}_{0-10}$ of $0.27(p=0.08)$ and $0.17(p=0.27)$, respectively (Fig. $4 b)$. However, the drought effect on the $\mathrm{PCWU}_{0-10}$ of $T$. pratense was inverted in mixture compared to monoculture as $\mathrm{PCWU}_{0-10}$ decreased with $0.23(p<0.05)$ and $0.28(p=0.07)$, for 2011 and 2012 respectively, resulting in a borderline significant $(p=0.05)$ water supply $\times$ species $\times$ diversity interaction (Figs. 2f-j, 4a, b and Table S4 in the Supplement).

\subsubsection{Differences among species’ monocultures}

There was a significant effect of plant species in monoculture ( $p<0.01$, Table S4 in the Supplement, Fig. 2) on the inferred depth of water uptake and the $\mathrm{PCWU}_{0-10}$, when grown in monoculture. For the two shallow-rooting species L. perenne and $T$. repens, water uptake was concentrated in the top 0 10 soil depth interval $\left(10 \mathrm{~cm}\right.$ depth and $\mathrm{PCWU}_{0-10}=0.53$ averaged for both species and water supply treatments). In contrast, the deep-rooting $C$. intybus mainly relied on deeper soil layers $\left(25 \mathrm{~cm}\right.$ depth and $\left.\mathrm{PCWU}_{0-10}=0.16\right)$. Surprisingly, water uptake of the deep-rooting species $T$. pratense was comparable or even more shallow than for the shallow- rooting species in both experiments (on average $9.6 \mathrm{~cm}$ depth and $\mathrm{PCWU}_{0-10}=0.68$, Fig. 2).

\subsubsection{Effect of interspecific interactions in mixtures}

T. pratense showed a strong shift to deeper soil water uptake in response to being grown in mixture compared to monoculture. The $\mathrm{PCWU}_{0-10}$ averaged over the two experiments decreased by 0.17 and 0.67 under control and drought conditions, respectively (Figs. 2 and $4 \mathrm{c}$, d). Similarly the inferred depth of water uptake increased from 12.8 to $16.8 \mathrm{~cm}$ and from 6.4 to $17.0 \mathrm{~cm}$ under control and drought conditions, respectively. The opposite was found for the other species, which tended to move their water uptake to shallower soil depth intervals resulting in a significant $(p<0.05$ and $p<0.01$ for depth of water uptake and $\mathrm{PCWU}_{0-10}$, respectively) species $\times$ diversity interaction (Table $\mathrm{S} 4$ in the Supplement and Figs. 2 and 4c, d).

We calculated the proportional similarity (Eq. 1) of the proportional water contribution of the different soil depth intervals to assess whether this shift in response to diversity resulted in reduced similarity between shallow- and deep-rooting species in mixtures compared to monocultures. The proportional similarity of mixed- and shallow-rooting species pairs was the same in monoculture compared to mixture, whereas the proportional similarity of the deep-rooting species pair $C$. intybus-T. pratense actually increased in mixtures compared to monocultures (significant rooting depth pair $\times$ diversity interaction, $p<0.001$, Fig. 5, Table S5 in the Supplement).

\section{Discussion}

\subsection{The effect of drought on the depth of water uptake}

In line with our hypothesis, under drought compared to control conditions, L. perenne, $T$. repens and $C$. intybus substantially decreased the proportional water uptake from the 0 $10 \mathrm{~cm}$ soil depth interval when grown in monoculture, and instead increased the proportional uptake from deeper and less dry soil layers. In contrast, T. pratense grown in monoculture actually shifted its proportional water uptake to more shallow soil depths under drought compared to control conditions, consistent for the two experiments. We do not have a clear explanation for this upward shift and it is contrary to general expectation, but the effect was clear and consistent for both experimental sites/years. The soil moisture content and distribution throughout the soil profile was similar to the other plant communities (no significant effect of community, Table S1 in the Supplement), and does not indicate increased water extraction from the top soil layer. Of all the species, the dry matter yield of $T$. pratense was least affected by the drought treatment (Table 2). Changes in pre-dawn leaf water potential in response to drought were similar for $T$. pratense 

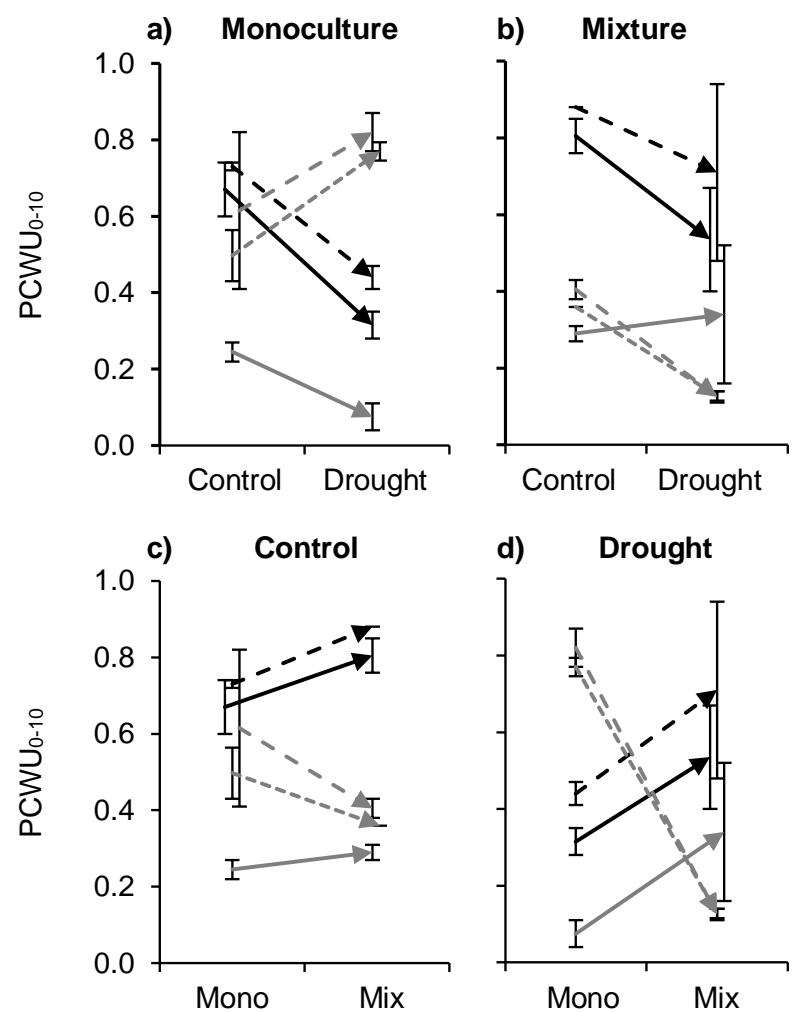

d) Drought

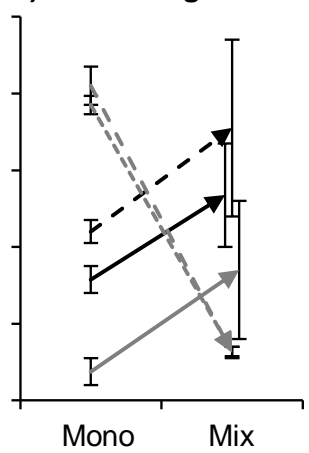

$\longrightarrow$ L perenne

$\rightarrow$ T repens

$\longrightarrow$ intybus

$\rightarrow$ T pratense 2012

$\ldots$ T pratense 2011

Figure 4. The shift in proportional contribution to plant water uptake from the $0-10 \mathrm{~cm}$ soil depth interval (PCWU $\left.\mathrm{P}_{0-10}\right)$ of shallow-rooting species (L. perenne and T. repens) and deep-rooting species (C. intybus and T. pratense 2011, 2012) as a result of water supply (a, b: control and drought) and diversity (c, d, monoculture and mixture). These graphs are based on the mean values presented in Fig. $2 \mathrm{f}-\mathrm{j}$, error bars represent one SE, $n=2$ (for exceptions see Fig. 2).
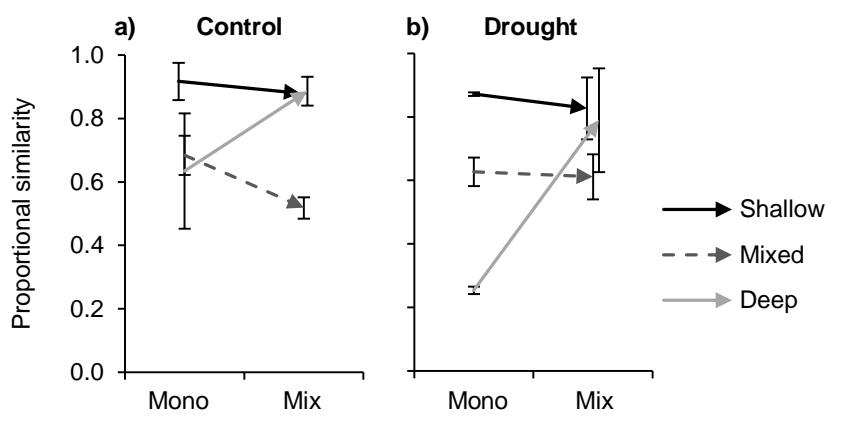

Figure 5. The proportional similarity (Eq. 1) of the proportional water uptake from the different soil depth intervals of shallow-rooting (L. perenne-T. repens), mixed-rooting (refers to combinations of shallow- and deep rooting species, and is the mean of $L$. perenne-C. intybus, L. perenne-T. pratense; T. repens-C. intybus; T. repens-T. pratense) and deep-rooting ( $C$. intybus $-T$. pratense) species pairs grown in monoculture (Mono) or mixture (Mix) under (a) control and (b) drought conditions in Reckenholz 2012. and $T$. repens and provided no evidence for differences in stomatal control (unpublished data).

There are very few data on the effect of drought on the depth of water uptake in grassland systems in the literature, and the findings are highly variable. Grieu et al. (2001) reported a substantial increase in the soil water uptake from deeper soil layers by $L$. perenne and $T$. repens seedlings grown in containers under moderate soil water deficit. In contrast, using the natural abundance $\delta^{18} \mathrm{O}$ technique, Prechsl (2013) found that mixed C3 grassland communities (dominated by Phleum pratense, Lolium multiflorum, Poa pratensis, Taraxacum officinale, Trifolium repens and Rumex $o b-$ tusifolius) subjected to artificial summer drought relied strongly on the topsoil $(0-10 \mathrm{~cm})$ for water (about $56 \%$ ) during drought, whereas the roots of plants that were not subjected to drought shifted to deeper soil layers during the summer months and relied less on the topsoil (about $30 \%$ ). These results were reflected in changes in root biomass at the different soil depth intervals. Similarly, a number of studies using natural abundance $\delta^{18} \mathrm{O}$ techniques (Asbjornsen et al., 2008; Nippert and Knapp, 2007a, b) or deuterium oxide labelling techniques (Kulmatiski and Beard, 2013) focusing on C4 grasses and herbaceous species grown in combination with shrubs or trees, show that the grasses tended to solely rely 
Table 2. Average aboveground dry matter yield $\left(\mathrm{kg} \mathrm{ha}^{-1}\right.$, SE in parentheses, $\left.n=3\right)$ of the plant communities and the proportion of dry matter yield of the sown species in the mixture under control and drought conditions during the final cut of the drought period in Tänikon (2011) and Reckenholz (2012) (see Tables S2 and S3 in the Supplement for statistical significance of treatment effects).

\begin{tabular}{|c|c|c|c|c|c|c|c|c|c|c|}
\hline \multirow[b]{3}{*}{ Community } & \multicolumn{10}{|c|}{ Dry matter yield $\left(\mathrm{kg} \mathrm{ha}^{-1}\right)$} \\
\hline & \multicolumn{5}{|c|}{ Tänikon (2011) } & \multicolumn{5}{|c|}{ Reckenholz (2012) } \\
\hline & \multicolumn{2}{|c|}{ Control } & \multicolumn{2}{|c|}{ Drought } & \multirow[t]{2}{*}{$\%$ change $^{a}$} & \multicolumn{2}{|c|}{ Control } & \multicolumn{2}{|c|}{ Drought } & \multirow[t]{2}{*}{$\%$ change $^{\mathrm{a}}$} \\
\hline Monocultures & & & & & & & & & & \\
\hline L. perenne & 1355 & (98.4) & 479 & (186.7) & $-65 \%$ & 682 & $(78.2)$ & 166 & $(46.7)$ & $-76 \%$ \\
\hline T. repens & 1763 & $(34.5)$ & 1523 & (74.4) & $-14 \%$ & 1197 & (128.9) & 789 & $(80.0)$ & $-34 \%$ \\
\hline C. intybus & 1477 & $(179.8)$ & 935 & (78.3) & $-37 \%$ & 2062 & (143.3) & 787 & $(40.2)$ & $-62 \%$ \\
\hline T. pratense & 2841 & (103.2) & 2791 & $(149.5)$ & $-2 \%$ & 3232 & (193.2) & 2551 & $(358.8)$ & $-21 \%$ \\
\hline Predicted mixture & 2076 & (109.1) & 1462 & $(98.0)$ & $-30 \%$ & 1999 & (183.3) & 1396 & $(270.0)$ & $-30 \%$ \\
\hline Mixture & 2113 & $(363.8)$ & 2110 & $(378.4)$ & $0 \%$ & 2955 & (187.4) & 1665 & $(262.0)$ & $-44 \%$ \\
\hline
\end{tabular}

Proportion of dry matter yield of sown species in the mixture

\begin{tabular}{lcccccccc}
\cline { 2 - 10 } & \multicolumn{4}{c}{ Tänikon (2011) } & \multicolumn{3}{c}{ Reckenholz (2012) } \\
\hline Species $^{c}$ & \multicolumn{2}{c}{ Control } & \multicolumn{2}{c}{ Drought } & \multicolumn{2}{c}{ Control } & \multicolumn{2}{c}{ Drought } \\
\hline L. perenne & 0.26 & $(0.04)$ & 0.24 & $(0.01)$ & 0.19 & $(0.09)$ & 0.10 & $(0.03)$ \\
T. repens & 0.07 & $(0.02)$ & 0.21 & $(0.06)$ & 0.04 & $(0.02)$ & 0.02 & $(0.01)$ \\
C. intybus & 0.13 & $(0.05)$ & 0.06 & $(0.03)$ & 0.06 & $(0.02)$ & 0.08 & $(0.01)$ \\
$T$. pratense & 0.52 & $(0.03)$ & 0.43 & $(0.04)$ & 0.59 & $(0.23)$ & 0.67 & $(0.16)$ \\
Dead & 0.02 & $(0.01)$ & 0.06 & $(0.02)$ & 0.12 & $(0.10)$ & 0.13 & $(0.12)$ \\
\hline
\end{tabular}

a (Drought - Control)/Control. ${ }^{b}$ The predicted mixture yield is calculated based on the monoculture yields multiplied by the species' relative abundances (each species' proportional contribution to aboveground biomass) in the previous harvest. ${ }^{\mathrm{c}}$ The proportion of unsown species in community dry matter yield was less than 0.0025 .

on shallow soil water, whereas shrubs and trees are more dependent on deeper soil water $(30 \mathrm{~cm}$ to $>150 \mathrm{~cm}$ soil depth) under natural seasonal drought conditions.

Also, reported responses of root growth to drought are variable. For example, Garwood and Sinclair (1979) reported a slight increase in percentage of $L$. perenne root length in the $0-10 \mathrm{~cm}$ soil depth under non-irrigated compared to irrigated plots (72 and $63 \%$ respectively) whereas Skinner (2008) found that mixtures of $L$. perenne and T. repens and $L$. perenne, $T$. repens and $C$. intybus had decreased root counts in the upper $40 \mathrm{~cm}$ and increased root counts at lower depths in drought stressed plots compared to control plots.

There are a number of reasons that may explain the different findings. Firstly, the severity and length of the drought will affect the plant water availability throughout the soil profile and therefore the impact of the drought. For example, during the drought period in our study, water availability was more limited in the $0-10 \mathrm{~cm}$ soil layer compared to the deeper soil layers (Fig. 1a, b). During the natural seasonal drought reported by Kulmatiski and Beard (2013), the water availability under drought conditions did not increase with soil depth within the rooting zone, and therefore, under those conditions, there is no obvious benefit for relatively shallow rooting species to invest in root growth to explore deeper layers. Other studies do not include sufficiently detailed infor- mation on soil water availability throughout the profile (Nippert and Knapp, 2007a; Asbjornsen et al., 2008), which emphasises the importance of measuring and reporting the soil moisture content throughout the rooting zone (Vicca et al., 2012).

Secondly, differences in species and plant communities may affect the response to drought. Our results show that plants grown in mixtures can have a different response to drought compared to their response in monoculture. For example, in contrast to its unexpected increase in the $\mathrm{PCWU}_{0-10}$ under drought conditions in monoculture, $T$. pratense decreased $\mathrm{PCWU}_{0-10}$ in response to drought when grown in mixture (Fig. 4b). Also, for T. repens and $C$. intybus the response to drought was much less pronounced when grown in mixtures compared to monocultures. Most of the studies above (Nippert and Knapp, 2007a; b; Asbjornsen et al., 2008; Kulmatiski and Beard, 2013; Prechsl, 2013) only look at the response in mixtures and not monocultures. Also they are based on very different systems of relatively shallow-rooting grasses and herbaceous species with deep-rooting shrubs or trees (with a much deeper rooting depth) (Nippert and Knapp, 2007a, b; Asbjornsen et al., 2008; Kulmatiski and Beard, 2013). In such systems, there is a competitive benefit for grasses to focus water uptake in surface soils due to their fibrous root morphology and a greater 
ability to respond to pulses in water availability (Nippert and Knapp, 2007b; Caldwell and Richards, 1986).

\subsection{Depth of water uptake of shallow- and deep-rooting species}

The two shallow-rooting species in this study (L. perenne and T. repens), had a significantly higher proportional water uptake from the shallow $(0-10 \mathrm{~cm})$ soil depth interval compared to the deep-rooting species $C$. intybus, showing that these deep- and shallow-rooting species occupy distinctly different vertical niches in relation to water uptake. This is in line with work by Pirhofer-Walzl et al. (2013) who reported that the proportion of ${ }^{15} \mathrm{~N}$ uptake from shallow root layers $(0-40 \mathrm{~cm})$ decreased in the order $L$. perenne $>T$. repens $>C$. intybus.

However, in contrast to our expectation, the depth of water uptake of the deep-rooting species $T$. pratense grown in monoculture tended to be shallower than the two shallowrooting species. We classified $T$. pratense as a deep-rooting species because it has tap roots, which can access deeper soil layers (Black et al., 2009). However, the $\mathrm{d}^{18} \mathrm{O}$ results indicate that the presence of roots in a particular soil layer is not necessarily equivalent to root activity, which has been confirmed in other studies (Nippert and Knapp, 2007a; Kulmatiski and Beard, 2013). In the current study, the deep-rooting $T$. pratense actually had shallow water uptake in monoculture, and it would seem that the plant rooting depth determines the potential range or plasticity in depth of water uptake rather than the actual depth of water uptake. Indeed, the plasticity of $T$. pratense in relation to depth of water uptake was very large and the $\mathrm{PCWU}_{0-10}$ ranged from 0.13 to 0.82 , which could have clear competitive advantages. Under control conditions, when water availability was not limited, uptake from shallower soil layers (compared to deeper) would be beneficial to the plant since there would be a shorter path length for transport, and therefore a reduced gradient in water potential required for movement. The fact that the other deep-rooting species $C$. intybus relied on deeper soil water under control conditions even when grown in monoculture, indicates that $C$. intybus roots may have a lower plasticity for water uptake from different soil depths compared to $T$. pratense.

This research shows that classification of species according to rooting depth may be of limited value, as the depth of main root activity depends on the specific conditions. Similarly, Durand et al. (1997) demonstrated that L. perenne could extract water from very similar depth as $F$. arundinacea, a renowned deep-rooted species.

\subsection{Shift in depth of water uptake in mixed communities}

We hypothesised that shallow-rooting species would move their water uptake to more shallow soil depth intervals and deep-rooting species to deeper soil depth intervals in mixtures compared to monocultures. Our results partly support this hypothesis as both shallow-rooting species $L$. perenne and $T$. repens tended to take up water from shallower soil depth intervals when grown in mixtures compared to monocultures (Fig. 4c, d). Additionally, the deep-rooting species T. pratense dramatically increased its proportional water uptake from deeper soil layers in mixtures compared to monocultures, particularly under drought conditions. However, the opposite was true for the other deep-rooting species $C$. intybus. The diverging response of $C$. intybus may be explained by the fact that $T$. pratense was the dominant deep-rooting species (aboveground species' proportions were on average 55 and $8 \%$ for $T$. pratense and C. intybus, respectively), which may have outcompeted $C$. intybus at the deeper soil levels forcing it upward instead.

This niche differentiation did not result in a reduction of niche overlap between deep- and shallow-rooting species, as the proportional similarity of PCWU of the different soil depth intervals between shallow- and deep-rooting species did not decrease in mixtures compared to monocultures (Fig. 5). This was the result of (1) the increase in proportional similarity between $C$. intybus and the shallow-rooting species and (2) the net effect of the strong change to deeper depth for $T$. pratense was limited under drought conditions, since it started from a very shallow depth when grown in monoculture (Fig. 4c, d). However, the strong dominance of T. pratense compared to the other species in terms of aboveground biomass may limit the value of the proportional similarity as an indication of community resource utilisation, since the contributions of all species are equally weighted. A substantial decrease in the proportional similarity of a pair of sub-dominant species may not affect the community resource utilisation (von Felten et al., 2009).

Our results show very little evidence for shifts in the vertical niche of shallow- and deep-rooting grassland species in mixtures compared to monocultures, and we could find none relating to depth of water uptake. Berendse (1982) showed that Plantago lanceolata acquired nutrients from deeper soil layers when grown together with the shallow-rooting grass Anthoxanthum odoratum than when grown in monoculture. Using ${ }^{15} \mathrm{~N}$ tracers to examine $\mathrm{N}$ partitioning, von Felten et al. $(2009,2012)$ showed that both niche breadth of individual species and niche overlap among species decreased with increasing species richness. Using a DNA-based technique to compare species-specific root distribution, Mommer et al. (2010) found that even though root biomass was significantly larger in a four-species grassland mixture compared to monocultures, this was not due to a shift in vertical niche distribution. In contrast, the rooting depth of the community 
tended to decrease rather than increase in mixtures compared to monocultures.

\subsection{Higher drought resistance for deep-rooting species?}

There was no clear link between interspecific differences in the depth of water uptake and the drought resistance (reduction in aboveground biomass under drought compared to control conditions). In line with our hypothesis, the shallowrooting $L$. perenne was most affected by drought. However, C. intybus, the species with the deepest water uptake, also had a very large reduction in the aboveground biomass under drought conditions. Interestingly, T. pratense, which was least affected by drought, also had the greatest plasticity in depth of water uptake. This suggests that there may be an indirect effect of rooting depth on drought resistance, as it determines the potential plasticity in the depth of water uptake (as discussed in Sect. 4.2). Additionally, other mechanisms such as species drought tolerance (Chaves et al., 2003) and nutrient availability (i.e. restrictions in available nitrogen under drought conditions, Hofer et al., 2013) are likely to affect the impact of drought on herbage dry matter yield.

\subsection{Does belowground vertical niche complementarity in depth of water uptake underpin the diversity effect in aboveground biomass?}

The $\delta^{18} \mathrm{O}$ results show that at least some of the species in this experiment occupied a distinctly different vertical niche in relation to proportional water uptake from different soil depth intervals and also showed shifts in niche occupation in response to diversity. However, the natural abundance $\delta^{18} \mathrm{O}$ method does not provide a quantitative measure of water uptake, as it is limited to measuring the proportional uptake from the different soil depth intervals. Therefore, it remains unknown whether total water uptake of the mixture was increased or not. Recent studies using ${ }^{15} \mathrm{~N}$ tracers allowed the measurement of total nutrient uptake in addition to the proportional contribution (Pirhofer-Walzl et al., 2013; von Felten et al., 2009, 2012; Kahmen et al., 2006). These studies reported that even though plants did occupy complementary spatial niches, this did not result in increased community nitrogen uptake in more diverse communities. von Felten et al. (2009) reported that the decrease in niche breadth and niche overlap mostly occurred among subordinate species or pairs of subordinate and dominant species, rather than among dominant species. Therefore, they concluded that niche differentiation with respect to $\mathrm{N}$ uptake from different chemical forms and soil depths was not a major driver of positive diversity-ecosystem functioning relationships in their experiment, but facilitated the co-existence of sub-ordinate species. In contrast, in the current study, the main shift in depth of water uptake in mixture compared to monoculture was for the dominant species, T. pratense.
In the current study, the biomass results showed that the observed mixture yield was higher than the predicted mixture yield (over-yielding), indicating a diversity effect. Our results suggest that differences in the depth of water uptake between species may have resulted in vertical niche complementarity in the depth of water uptake between deep- and shallow-rooting species, which may have contributed to this over-yielding. However, due to the lack of data on quantitative water uptake from different soil depths, we cannot provide direct evidence for this. Additionally, other factors, such as vertical soil niche complementarity for nutrients, or interactions between legumes and non-legumes, soil-biotic factors or a combination of factors may have also contributed to the diversity effect.

\subsection{Methodology}

The use of natural abundance $\delta^{18} \mathrm{O}$ to assess the effect of drought on patterns of water use by co-occurring species worked well. We observed a clear soil gradient, which is common in soil depths up to $50 \mathrm{~cm}$ for perennial grass systems (Asbjornsen et al., 2007; Nippert and Knapp, 2007a). The $\delta^{18} \mathrm{O}$ signal in soil water was more negative for drought compared to the control treatment. This might be the result of reduced evaporation from the drought plots, related to the reduction in incoming radiation under the drought shelters (reduction in incoming PAR of 10-28\%). However, this effect is somewhat reduced because vegetation ground cover tended to be lower and temperature higher under drought conditions. Monthly rainfall $\mathrm{d}^{18} \mathrm{O}$ isotopic composition data from the Swiss National Network for the Observation of Isotopes in the Water Cycle (ISOT) (Schürch et al., 2003) show that the $\mathrm{d}^{18} \mathrm{O}$ of rainwater was less negative during the drought period compared to the preceding months (difference of 2.1 and 2.9 during 2011 and 2012, respectively, Fig. S3 in the Supplement). Therefore, the control plots may have become relatively enriched due to the increased enrichment of rain water during the drought period.

In general, there was a good correlation between the depth of water uptake estimated through the direct inference method and the IsoSource model $(r=0.86)$, and the trends in relation to species, diversity and water supply were similar for both methods. However, the treatment effects were more pronounced for the IsoSource model, and therefore resulted in more significant effects. It should be noted that these treatment effects are based on the mean of the frequency distribution, and that the full range (1-99 percentile) of the possible proportional contribution showed overlap for some treatments (Fig. $2 \mathrm{f}-\mathrm{j}$ ). The two main drawbacks of the direct inference approach are (1) the assumption that plants rely on water uptake of one single mean depth and (2) that the determination of this soil depth can be arbitrary, particularly in situations when there is no strong gradient in the soil $\delta^{18} \mathrm{O}$ profile (Asbjornsen et al., 2007). An advantage of the IsoSource model over the direct inference method is the 
possibility to quantitatively describe relative contributions of water from the different soil depth intervals in a systematic way (Phillips and Gregg, 2003).

For practical reasons, the $\delta^{18} \mathrm{O}$ sampling depth was limited to $40 \mathrm{~cm}$ soil depth. However, it is not unlikely that water uptake from below this depth occurred (Skinner, 2008; Pirhofer-Walzl et al., 2013; Garwood and Sinclair, 1979). This would not have affected the mean inferred depth of water uptake, as these values were all well above $40 \mathrm{~cm}$ (Fig. 2a-e). In order to get an idea of the potential effect of limiting the soil sampling depth to $40 \mathrm{~cm}$ on the output of the IsoSource model, we re-ran the model with estimated $\delta^{18} \mathrm{O}$ values for the $40-50 \mathrm{~cm}$ soil depth interval. We assumed that the decline in $\delta^{18} \mathrm{O}$ with increasing soil depth would start to "level out" at this depth (see also Fig. 2), and estimated the $\delta^{18} \mathrm{O}$ value for the $40-50 \mathrm{~cm}$ soil depth interval as $\delta^{18} \mathrm{O}_{30-40}+\left(\delta^{18} \mathrm{O}_{30-40}-\delta^{18} \mathrm{O}_{20-30}\right) 2^{-1}$. The resulting estimates for $\mathrm{PCWU}_{0-10}$ were highly correlated to the original estimates $\left(r^{2}=0.99\right)$ and were marginally higher $(0.51$ instead of 0.49), strengthening the evidence for the relative reliance on shallow soil depths. As a result, adding an extra (estimated) depth to the IsoSource model input had no effect on the observed trends in response to drought and diversity.

In this experiment, we simulated summer drought by using rainout shelters for a period of 9 weeks, resulting in a significant reduction in soil moisture content in the drought plots. The use of shelters resulted in an increase in the mean air temperature (3\%), soil temperature $(8 \%)$ and a decrease in air relative humidity $(-2 \%)$, which can potentially exacerbate the effect of rain exclusion alone. De Boeck and Verbeeck (2011) showed that naturally occurring drought was accompanied by similar changes in temperature $(11.1 \%)$ and relative humidity $(-11.6 \%)$. In contrast, the shelters reduced the incoming PAR (10-28\%), which may have limited the water loss through evapo-transpiration in the drought treatment. This re-emphasises the importance of measuring and reporting the soil moisture content throughout the rooting zone (Vicca et al., 2012) as the main indicator of the severity of the drought treatment. In our experiment, soil moisture content was strongly reduced in the drought compared to the control plots, particularly in the top soil.

\section{Conclusions}

- The $\delta^{18} \mathrm{O}$ natural abundance method provided new insights into the depth of water uptake of grassland species. There were large treatment effects on the depth of water uptake of $T$. pratense in particular.

- In line with our hypothesis, monocultures of L. perenne, $T$. repens and $C$. intybus moved their water uptake to deeper soil depth intervals in response to drought. However, $T$. pratense in monoculture did the opposite, and we have no clear explanation for this.
- As expected, the two shallow-rooting species had higher proportional water uptake from the shallow soil depth interval compared to the deep-rooting $C$. intybus. However, the deep-rooting $T$. pratense grown in monoculture relied more on shallow soil water than the shallowrooting species.

- As hypothesised, interspecific interactions in mixtures resulted in a shift in the depth of water uptake, which tended to become shallower for the shallow-rooting species and deeper for the deep-rooting $T$. pratense. However, this did not result in a net reduction in proportional similarity (niche overlap) between shallow- and deep-rooting species in mixture.

- There was no clear link between depth of water uptake and resistance to drought, as the species with the deepest water uptake (C. intybus) was also most affected by drought. $T$. pratense, which was least affected by drought, also had the greatest plasticity in depth of water uptake. This suggests that there may be an indirect effect of rooting depth on drought resistance, as it determines the potential plasticity in the depth of water uptake.

\section{The Supplement related to this article is available online at doi:10.5194/bg-11-4493-2014-supplement.}

Acknowledgements. N. J. Hoekstra was funded by the Irish Research Council, co-funded by Marie Curie Actions under FP7. The field experiments were supported by the European Community's Seventh Framework Programme (FP7/2007-2013) under the grant agreements FP7-266018 (AnimalChange) and FP7-244983 (MultiSward). The authors would like to thank Nina Buchmann, Ulrich Prechsl and Annika Ackermann at ETH Zürich for the introduction to the theory and practicalities of the $\delta^{18} \mathrm{O}$ method and the use of water extraction facilities at ETH. We are grateful to B. Eickhoff, S. Husse, C. Stutz, R. Gago, R. Lopez and A. Kundela for help with the $\mathrm{O}^{18}$ sampling and processing and running the field experiment. We thank M. Suter for his help with statistical analysis.

Edited by: M. Bahn

\section{References}

Asbjornsen, H., Mora, G., and Helmers, M. J.: Variation in water uptake dynamics among contrasting agricultural and native plant communities in the Midwestern U.S, Agr. Ecosyst. Environ., 121, 343-356, 2007.

Asbjornsen, H., Shepherd, G., Helmers, M., and Mora, G.: Seasonal patterns in depth of water uptake under contrasting annual and perennial systems in the Corn Belt Region of the Midwestern U.S, Plant Soil, 308, 69-92, 2008. 
Berendse, F.: Competition between plant-populations with different rooting depths. 3. Field experiments, Oecologia, 53, 50-55, 1982.

Black, A., Laidlaw, A., Moot, D., and O'Kiely, P.: Comparative growth and management of white and red clovers, Irish J. Agr. Food Res., 48, 149-166, 2009.

Brown, H., Moot, D., and Pollock, K.: Long term growth rates and water extraction patterns of dryland chicory, lucerne and red clover, Legumes for dryland pastures. Grassland Research and Practice Series, 11, 91-99, 2003.

Brunel, J.-P., Walker, G. R., and Kennett-Smith, A. K.: Field validation of isotopic procedures for determining sources of water used by plants in a semi-arid environment, J. Hydrol., 167, 351-368, 1995.

Caldwell, M. M. and Richards, J.: Competing root systems: morphology and models of absorption, On the economy of plant form and function, Cambridge University Press, Cambridge, 1986.

Chaves, M. M., Maroco, J. P., and Pereira, J. S.: Understanding plant responses to drought - from genes to the whole plant, Funct. Plant Biol., 30, 239-264, 2003.

Christensen, J. H. and Christensen, O. B.: Climate modelling: severe summertime flooding in Europe, Nature, 421, 805-806, 2003.

Coelho, E. F. and Or, D.: Root distribution and water uptake patterns of corn under surface and subsurface drip irrigation, Plant Soil, 206, 123-136, 1999.

Colwell, R. K. and Futuyma, D. J.: On the measurement of niche breadth and overlap, Ecology, 52, 567-576, 1971.

Dawson, T. E. and Ehleringer, J. R.: Isotopic enrichment of water in the "woody" tissues of plants: Implications for plant water source, water uptake, and other studies which use the stable isotopic composition of cellulose, Geochim. Cosmochim. Ac., 57, 3487-3492, 1993.

Dawson, T. E., Mambelli, S., Plamboeck, A. H., Templer, P. H., and Tu, K. P.: Stable isotopes in plant ecology, Annu. Rev. Ecol. Evol. S., 33, 507-559, 2002.

De Boeck, H. J. and Verbeeck, H.: Drought-associated changes in climate and their relevance for ecosystem experiments and models, Biogeosciences, 8, 1121-1130, doi:10.5194/bg-8-11212011, 2011.

De Boeck, H. J., Lemmens, C. M. H. M., Zavalloni, C., Gielen, B., Malchair, S., Carnol, M., Merckx, R., Van den Berge, J., Ceulemans, R., and Nijs, I.: Biomass production in experimental grasslands of different species richness during three years of climate warming, Biogeosciences, 5, 585-594, doi:10.5194/bg5-585-2008, 2008.

Durand, J.-L., Gastal, F., Etchebest, S., Bonnet, A.-C., and Ghesquière, M.: Interspecific variability of plant water status and leaf morphogenesis in temperate forage grasses under summer water deficit, Developments in Crop Science, 25, 135-143, 1997.

Durand, J. L., Bariac, T., Ghesquière, M., Biron, P., Richard, P., Humphreys, M., and Zwierzykovski, Z.: Ranking of the depth of water extraction by individual grass plants, using natural ${ }^{18} \mathrm{O}$ isotope abundance, Environ. Exp. Bot., 60, 137-144, 2007.

Durand, J.-L., Bariac, T., Rothfuss, Y., Richard, P., Biron, P., and Gastal, F.: Investigating the competition for water and the depth of water extraction in multispecies grasslands using ${ }^{18} \mathrm{O}$ natural abundance, in: Sustainable use of Genetic Diversity in Forage and Turf Breeding, edited by: Huyghe, C., Springer Netherlands, 205-209, 2010.

Ehleringer, J. and Osmond, C.: Stable isotopes, in: Plant physiological ecology: field methods and instrumentation, edited by: Pearcy, R., Ehleringer, J., Mooney, H., and Rundel, P., Chapman and Hall Ltd, 381-300, 1989.

Finn, J. A., Kirwan, L., Connolly, J., Sebastià, M. T., Helgadottir, A., Baadshaug, O. H., Bélanger, G., Black, A., Brophy, C., Collins, R. P., Čop, J., Dalmannsdóttir, S., Delgado, I., Elgersma, A., Fothergill, M., Frankow-Lindberg, B. E., Ghesquiere, A., Golinska, B., Golinski, P., Grieu, P., Gustavsson, A.-M., Höglind, M., Huguenin-Elie, O., Jørgensen, M., Kadziuliene, Z., Kurki, P., Llurba, R., Lunnan, T., Porqueddu, C., Suter, M., Thumm, U., and Lüscher, A.: Ecosystem function enhanced by combining four functional types of plant species in intensively managed grassland mixtures: a 3-year continental-scale field experiment, J. Appl. Ecol., 50, 365-375, 2013.

Garwood, E. A. and Sinclair, J.: Use of water by six grass species. 2. Root distribution and use of soil water, J. Agr. Sci., 93, 25-35, 1979.

Gilgen, A. K. and Buchmann, N.: Response of temperate grasslands at different altitudes to simulated summer drought differed but scaled with annual precipitation, Biogeosciences, 6, 2525-2539, doi:10.5194/bg-6-2525-2009, 2009.

Grieu, P., Lucero, D., Ardiani, R., and Ehleringer, J.: The mean depth of soil water uptake by two temperate grassland species over time subjected to mild soil water deficit and competitive association, Plant Soil, 230, 197-209, 2001.

Grime, J. P., Brown, V. K., Thompson, K., Masters, G. J., Hillier, S. H., Clarke, I. P., Askew, A. P., Corker, D., and Kielty, J. P.: The response of two contrasting limestone grasslands to simulated climate change, Science, 289, 762-765, 2000.

Hector, A., Schmid, B., Beierkuhnlein, C., Caldeira, M. C., Diemer, M., Dimitrakopoulos, P. G., Finn, J. A., Freitas, H., Giller, P. S., Good, J., Harris, R., Hoegberg, P., Huss-Danell, K., Joshi, J., Jumpponen, A., Koerner, C., Leadley, P. W., Loreau, M., Minns, A., Mulder, C. P. H., O’Donovan, G., Otway, S. J., Pereira, J. S., Prinz, A., Read, D. J., Scherer-Lorenzen, M., Schulze, E.-D., Siamantziouras, A. S. D., Spehn, E. M., Terry, A. C., Troumbis, A. Y., Woodward, F. I., Yachi, S., and Lawton, J. H.: Plant diversity and productivity experiments in European grasslands, Science, 286, 1123-1127, 1999.

Hofer, D., Suter, M., Hoekstra, N., Buchmann, N., and Lüscher, A.: $\mathrm{N}_{2}$ fixing legumes in intensively managed grassland are less affected by drought than non-fixing species, Plants in a Changing Climate - Plant Science Centre Symposium 2013, Zurich, 2013.

IPCC: Climate Change 2013: The Physical Science Basis, Contribution of Working Group I to the Fifth Assessment Report of the Intergovernmental Panel on Climate Change, edited by: Stocker, T. F., Qin, D., Plattner, G.-K., Tignor, M., Allen, S. K., Boschung, J., Nauels, A., Xia, Y., Bex, V., and Midgley, P. M., Cambridge University Press, Cambridge, United Kingdom and New York, NY, USA, 1535 pp., 2013.

Jupp, A. P. and Newman, E. I.: Morphological and Anatomical Effects of Severe Drought on the Roots of Lolium perenne L., New Phytol., 105, 393-402, 1987.

Kahmen, A., Perner, J., and Buchmann, N.: Diversity-dependent productivity in semi-natural grasslands following climate perturbations, Funct. Ecol., 19, 594-601, 2005. 
Kahmen, A., Renker, C., Unsicker, S. B., and Buchmann, N.: Niche complementarity for nitrogen: An explanation for the biodiversity and ecosystem functioning relationship?, Ecology, 87, 12441255, 2006.

Kennedy, T. A., Naeem, S., Howe, K. M., Knops, J. M. H., Tilman, D., and Reich, P.: Biodiversity as a barrier to ecological invasion, Nature, 417, 636-638, 2002.

Kirwan, L., Lüscher, A., Sebastia, M. T., Finn, J. A., Collins, R. P., Porqueddu, C., Helgadottir, A., Baadshaug, O. H., Brophy, C., Coran, C., Dalmannsdottir, S., Delgado, I., Elgersma, A., Fothergill, M., Frankow-Lindberg, B. E., Golinski, P., Grieu, P., Gustavsson, A. M., Hoeglind, M., Huguenin-Elie, O., Iliadis, C., Jorgensen, M., Kadziuliene, Z., Karyotis, T., Lunnan, T., Malengier, M., Maltoni, S., Meyer, V., Nyfeler, D., NykanenKurki, P., Parente, J., Smit, H. J., Thumm, U., and Connolly, J.: Evenness drives consistent diversity effects in intensive grassland systems across 28 European sites, J. Ecol., 95, 530-539, 2007.

Kulmatiski, A. and Beard, K. H.: Root niche partitioning among grasses, saplings, and trees measured using a tracer technique, Oecologia, 171, 25-37, 2013.

Lehner, B., Döll, P., Alcamo, J., Henrichs, T., and Kaspar, F.: Estimating the impact of global change on flood and drought risks in Europe: a continental, integrated analysis, Clim. Change, 75, 273-299, 2006.

Mommer, L., Wagemaker, C., De Kroon, H., and Ouborg, N.: Unravelling below-ground plant distributions: a real-time polymerase chain reaction method for quantifying species proportions in mixed root samples, Mol. Ecol. Res., 8, 947-953, 2008.

Mommer, L., Van Ruijven, J., De Caluwe, H., Smit-Tiekstra, A. E., Wagemaker, C. A. M., Joop Ouborg, N., Bögemann, G. M., Van Der Weerden, G. M., Berendse, F., and De Kroon, H.: Unveiling below-ground species abundance in a biodiversity experiment: a test of vertical niche differentiation among grassland species, J. Ecol., 98, 1117-1127, 2010.

Nippert, J. B. and Knapp, A.: Linking water uptake with rooting patterns in grassland species, Oecologia, 153, 261-272, 2007a.

Nippert, J. B. and Knapp, A. K.: Soil water partitioning contributes to species coexistence in tallgrass prairie, Oikos, 116, 10171029, 2007b.

Nyfeler, D., Huguenin-Elie, O., Suter, M., Frossard, E., Connolly, J., and Lüscher, A.: Strong mixture effects among four species in fertilized agricultural grassland led to persistent and consistent transgressive overyielding, J. Appl. Ecol., 46, 683-691, 2009.

Nyfeler, D., Huguenin-Elie, O., Suter, M., Frossard, E., and Lüscher, A.: Grass-legume mixtures can yield more nitrogen than legume pure stands due to mutual stimulation of nitrogen uptake from symbiotic and non-symbiotic sources, Agr. Ecosyst. Environ., 140, 155-163, 2011.

Phillips, D. and Gregg, J.: Source partitioning using stable isotopes: coping with too many sources, Oecologia, 136, 261-269, 2003.

Phillips, D., Newsome, S., and Gregg, J.: Combining sources in stable isotope mixing models: alternative methods, Oecologia, 144, 520-527, 2005.
Pinheiro, J. C. and Bates, D. M.: Mixed-effects Models in S and S-Plus, 2nd Edn., Springer, New York, 2009.

Pirhofer-Walzl, K., Eriksen, J., Rasmussen, J., Høgh-Jensen, H., and Søegaard, K.: Effect of four plant species on soil ${ }^{15} \mathrm{~N}$-access and herbage yield in temporary agricultural grasslands, Plant Soil, 371, 313-325, 2013.

Prechsl, U. E.: Using stable oxygen and hydrogen isotopes to assess plant water relations in grasslands exposed to drought, $\mathrm{PhD}, \mathrm{ETH}$ Zürich, http://e-collection.library.ethz.ch/view/eth:7471 (last access: 11 August 2014), 2013.

Schär, C., Vidale, P. L., Lüthi, D., Frei, C., Häberli, C., Liniger, M. A., and Appenzeller, C.: The role of increasing temperature variability in European summer heatwaves, Nature, 427, 332336, 2004.

Schürch, M., Kozel, R., Schotterer, U., and Tripet, J.-P.: Observation of isotopes in the water cycle - the Swiss National Network (NISOT), Environ. Geol., 45, 1-11, 2003.

Sharp, R. and Davies, W.: Root growth and water uptake by maize plants in drying soil, J. Exp. Bot., 36, 1441-1456, 1985.

Skinner, R. H.: Yield, root growth, and soil water content in drought-stressed pasture mixtures containing chicory, Crop Sci., 48, 380-388, 2008.

Socki, R., Karlsson, H., and Gibson, E.: Extraction technique for the determination of oxygen-18 in water using preevacuated glass vials, Anal. Chem., 64, 829-831, 1992.

Tilman, D., Wedin, D., and Knops, J.: Productivity and sustainability influenced by biodiversity in grassland ecosystems, Nature, 379, 718-720, 1996.

Tilman, D., Knops, J., Wedin, D., and Reich, P.: Plant diversity and composition: effects on productivity and nutrient dynamics of experimental grasslands, in: Biodiversity and Ecosystem functioning, Synthesis and perpectives, edited by: Loreau, M., Naeem, S., and Inchausti, P., Oxford University Press, 21-35, 2002.

Vicca, S., Gilgen, A., Camino Serrano, M., Dreesen, F., Dukes, J., Estiarte, M., Gray, S., Guidolotti, G., Hoeppner, S., and Leakey, A.: Urgent need for a common metric to make precipitation manipulation experiments comparable, New Phytol., 195, 518-522, 2012.

Vogel, A., Scherer-Lorenzen, M., and Weigelt, A.: Grassland resistance and resilience after drought depends on management intensity and species richness, Plos One, 7, e36992, doi:10.1371/journal.pone.0036992, 2012.

von Felten, S. and Schmid, B.: Complementarity among species in horizontal versus vertical rooting space, J. Plant Ecol., 1, 33-41, 2008.

von Felten, S., Hector, A., Buchmann, N., Niklaus, P. A., Schmid, B., and Scherer-Lorenzen, M.: Belowground nitrogen partitioning in experimental grassland plant communities of varying species richness, Ecology, 90, 1389-1399, 2009.

von Felten, S., Niklaus, P. A., Scherer-Lorenzen, M., Hector, A., and Buchmann, N.: Do grassland plant communities profit from N partitioning by soil depth?, Ecology, 93, 2386-2396, 2012. 